\title{
A role for GLABRA1 in dark-induced senescence*
}

\author{
Aleksandra Eckstein ${ }^{1,2}$, Joanna Grzyb³, Paweł Hermanowicz ${ }^{4}$, Justyna Łabuz ${ }^{4}$ \\ and Agnieszka Katarzyna Banaś1 1
}

1Department of Plant Biotechnology, Faculty of Biochemistry, Biophysics and Biotechnology, Jagiellonian University, Kraków, Poland; ${ }^{2}$ Department of Plant Physiology and Biotechnology, Faculty of Biology, University of Gdańsk, Gdańsk, Poland; '3epartment of Biophysics, Faculty of Biotechnology, University of Wrocław, Wrocław, Poland; 4Laboratory of Photobiology, The Malopolska Centre of Biotechnology, Jagiellonian University, Kraków, Poland

The GLABRA (GL1) gene, belonging to the transcription factor-encoding myb gene family, is responsible for trichome formation in Arabidopsis thaliana (L.) Heynh. The leaves and stems of glabra1 mutant plants are devoid of trichomes. Having an easily observable phenotype, the gl1 mutation was one of the first markers established for genetic mapping of Arabidopsis thaliana. Since then, the GL1 gene has been assigned roles in other processes, also related to leaf structure. In this study we present some previously undescribed effects of the gl1 mutation on dark-induced senescence. This process was induced by covering selected mature leaves of Columbia wild-type and gl1 Arabidopsis with black paper for 4 days, while the plants remained growing in a normal photoperiod. While no visible differences in the external symptoms of senescence could be observed in the darkened leaves, the expression of senescence-associated genes was significantly lower in gl1 plants as compared to the wild type. The darkening of leaves led to a decrease in photosynthetic activity and the expression of photosynthesis-associated genes, in comparison to the control leaves. This effect was much less pronounced in $g / 1$ than in the wild type plants. Therefore, gl1 plants seem to be less susceptible to dark-induced aging, suggesting a possible role for the GL1 gene in controlling the onset and progress of senescence. This result is also of practical importance, since $g / 1$ is the genetic background of many other mutants. It may therefore be advisable to revise some of the results obtained with such mutants in light of findings presented here.

Key words: GLABRA1, senescence, darkness, photosynthesis, photosynthetic pigments, trichomes

Received: 11 April, 2019; revised: 23 May, 2019; accepted: 29 May, 2019; available on-line: 30 June, 2019

๑e-mail: a_katarzyna.banas@uj.edu.pl

Acknowledgements of Financial Support: This research was supported by the Polish National Science Centre, grant no. UMO2011/03/D/NZ3/00210.

*A preliminary report on this subject was presented at the 46th Winter School of the Faculty of Biochemistry, Biophysics and Biotechnology, Jagiellonian University in Krakow, Zakopane, Poland, February 11th-15th 2019

Abbreviations: CAB, CHLOROPHYLL A/B BINDING PROTEIN; g/1, glabra1; $F_{v} / F_{m}$ maximum quantum yield of photosystem II; PAL1, PHENYLALANINE AMMONIA-LYASE 1; PSI/PSII, photosystem I/II; RbcS1A, RIBULOSE BISPHOSPHATE CARBOXYLASE SMALL CHAIN 1A, SAG, SENESCENCE ASSOCIATED GENE; SEN1, SENESCENCE1; WT, wild type

\section{INTRODUCTION}

Arabidopsis thaliana (L.) Heynh trichomes, the so called leaf hairs, are branched, non-glandular structures originating from single epidermal cells. Their formation is controlled by a complex interplay of several transcription factors, belonging to different families. GLABR A (GL1) was one of the first genes identified as being responsible for trichome development (Herman \& Marks, 1989; Marks \& Feldmann, 1989; Oppenheimer et al., 1991). It encodes an R2R3 MYB transcription factor, which along with one of the two redundantly acting basic helix-loop-helix (bHLH) transcription factors GLABRA3 (GL3) or ENHANCER OF GLABRA3 (EGL3), and TRANSPARENT TESTA GLABRA1 (T'TG1, WD40 family), forms the trichome activator complex (Hauser, 2014; Dai et al., 2016; Matías-Hernández et al., 2016). Activation of this complex (also called MBW: MYBbHLH-WD40), triggers the trichome formation pathway in a given epidermal cell, while inhibits this process in surrounding cells. This complex induces transcription of GLABRA2 (GL2) and other downstream genes required for trichome development (Dai et al., 2016). At the same time it also initiates expression of several R3 MYBs acting as trichome repressors: CAPRICE (CPC), ENHANCER OF TRIPTYCHON AND CAPRICE1 (ETC1), ETC3 and TRIPTYCHON (TRY) (MatíasHernández et al., 2016). These negative regulators move into adjacent cells, where they inhibit the formation of the activator complex by competing with GL1 for GL3 or EGL3 binding. Other R3 MYB trichome repressors are controlled by an independent pathway mediated by microRNA156 and SQUAMOSA PROMOTER BINDING PROTEIN LIKE (SPL), regulating temporal trichome patterning (Yu et al., 2010). Moreover, the phytohormones: gibberellins and cytokinins, act as positive regulators of trichome formation (Matías-Hernández et al., 2016).

Although they may seem inconspicuous, trichomes have a wide array of important physiological functions. Trichomes increase the light reflectance of leaves, protecting them against excessive heat and photoinhibition, as well as UV-B damage. The presence of trichomes affects such leaf properties as wettability, water repellence and boundary layer thickness, thus regulating transpiration, water uptake and gas exchange (Bickford, 2016). Trichomes also provide protection against biotic stresses, especially those caused by herbivorous insects (Hauser, 2014). The leaves and stems of glabra1 (gl1) mutant 
plants are devoid of trichomes, while some remain present on the leaf margins. Having an easily observable phenotype and exhibiting no other apparent abnormalities, the natural gll mutation was one of the first markers established for the genetic mapping of Arabidopsis in the 1960's (Redei \& Hirono, 1964; Koornneeff et al., 1982). Later, the gll mutation was introduced into the widely used Landsberg and Columbia ecotypes. Since then, gll has been used as a genetic background for generating other mutants. Recently, some other effects of the gll mutation, also related to leaf structure, were reported. gl1 Leaves exhibit a lower stomatal density and a less ordered pattern of stomatal distribution than wild type (WT) (Tsuji \& Coe, 2013). The gll mutation has been also found to affect cuticle formation (Xia et al., 2010). The defective structure of g/1 cuticle was caused by a reduced content of several cuticular wax components. This in turn compromised the systemic acquired resistance (SAR) of gll plants, as shown by their enhanced susceptibility to fungal pathogens.

In this study, we found a novel function of the GL1 transcription factor. The motivation came from some ambiguous results obtained previously using Arabidopsis mutants with a gll background. We found differences in the dark-induced chlorophyll degradation between WT Columbia and mutants with a gl1 background and gll plants (unpublished data). To clarify whether the lack of GLABRA1 is involved in the observed effect, we compared the process of dark-induced senescence in Arabidopsis thaliana WT Columbia and the gll mutant. We used an experimental protocol involving the darkening of individual leaves, while the plants remained in a normal photoperiod (Weaver \& Amasino, 2001; Keech et al., 2007). This model shares many common features with natural, age-dependent senescence, including leaf yellowing, chlorophyll degradation and induction of senescence associated genes ( $S A G s$ ) (van der Graaff et al., 2006). To assess the progress of senescence we used several well-established markers, such as photosynthetic efficiency and photosynthetic pigment content in the leaves (Weaver \& Amasino, 2001; Sztatelman et al., 2015). We also assessed expression of several genes involved in senescence (SENESCENCE ASSOCIATED GENES - SAG13, SAG12 and SENESCENCE1 - SEN1), photosynthesis (RIBULOSE BISPHOSPHATE CARBOXYLASE SMALL CHAIN $1 A-\operatorname{RbcS1} A$ and CHLOROPHYLL $A / B$ BINDING PROTEINS - $C A B s$, including $C A B 1$ and $C A B 2)$ and anthocyanin biosynthesis (PHENYLALANINE AMMONIA-LYASE 1 - PAL1). All genes selected for investigation in this study have been previously used in our work on darkening of detached Arabidopsis leaves (Sztatelman et al., 2015.)

\section{MATERIALS AND METHODS}

Plant material. Arabidopsis thatiana WT Columbia-0 and gl1 (CS28174) seeds were purchased from the Nottingham Arabidopsis Stock Center (NASC, Nottingham, UK). After sowing in Jiffy-7 pots (Jiffy International AS), the seeds were stratified at $4^{\circ} \mathrm{C}$ for 2 days. Plants were cultured in a Sanyo MLR $350 \mathrm{H}$ growth chamber, at $23^{\circ} \mathrm{C}$, $80 \%$ humidity, in a $14 \mathrm{~h}$ light $/ 10 \mathrm{~h}$ dark photoperiod and illuminated with fluorescent lamps (OSRAM L36W/77 and PHILIPS Master TL-D 36/W/840) with an average photosynthetic photon flux density of $70 \mu \mathrm{molm}^{-2} \mathrm{~s}^{-1}$. Plants used for experiments were 5-6 weeks old.
Light/dark treatment. Two or three adult, healthy leaves from each plant were darkened by wrapping in black paper. The plants remained in the growth chamber and after 4 days the darkened and non-darkened leaves were collected from each plant. Both darkened and nondarkened samples were chosen from leaves number 5 to 10 . Whole plants were dark-adapted for $16 \mathrm{~h}$ before leaf collection (starting with the onset of darkness in the growth chamber). The harvested leaves were either directly used for chlorophyll fluorescence measurements or frozen in liquid nitrogen and stored at $-80^{\circ} \mathrm{C}$ for further experiments (pigment extraction, RNA and protein isolation). Frozen samples consisted of 1-3 leaves $(g / 1)$ or 3 leaves (WT) pooled from different plants.

Pigment extraction/HPLC measurement. Leaf samples (50-200 $\mathrm{mg}$ of fresh mass) were ground in a mortar in 1-2 $\mathrm{ml}$ of methanol with a few grains of $\mathrm{CaCO}_{3}$. The homogenate was collected quantitatively and centrifuged, and the extraction of the pellet was repeated. Supernatants from both extractions were pooled and adjusted to known volume with methanol. Pigment separation, detection and quantitative analysis were performed according to (Sztatelman et al., 2015).

Measurement of chlorophyll fluorescence. The maximum quantum yield of photosystem II (PSII) ( $\mathrm{F}_{\mathrm{v}} /$ $\mathrm{F}_{\mathrm{m}}$ ) was measured using an Open FluorCam FC 800$\mathrm{O} / 1010$ imaging fluorometer. Detached leaves (darkened and non-darkened) were placed on water-soaked paper and dark-adapted for $30 \mathrm{~min}$. After recording the basal fluorescence $\left(\mathrm{F}_{0}\right)$ for $2 \mathrm{~s}$, samples were illuminated with saturating white light $\left(2000 \mu \mathrm{mol} \mathrm{m} \mathrm{m}^{-2} \mathrm{~s}^{-1}\right)$ for $960 \mathrm{~ms}$. The average $F_{v} / F_{m}$ value for each leaf was calculated using the FluorCam7 software.

RNA isolation and real-time PCR. Total RNA was extracted using the Spectrum Plant Total Kit (Sigma-Aldrich) and digested with DNaseI (Sigma-Aldrich) during purification on columns. RNA concentration was measured using a NanoDrop Lite (Thermo Fisher Scientific) spectrophotometer and its integrity was checked by electrophoresis in 1\% agarose gel. First-strand cDNA synthesis was performed using the RevertAid M-MuLV Reverse Transcriptase Kit (Thermo Fisher Scientific) with $1000 \mathrm{ng}$ of RNA and oligo(dT) ${ }_{18}$ primers. Real-time PCR was performed using SYBR Green JumpStart Taq ReadyMix (Sigma Aldrich) and a Rotor-Gene 6000 thermal cycler (Corbett Research, Australia) according to (Labuz et al., 2012), with the following modifications: reactions were run in triplicates, and UBC, UBQ10 and $S A N D$ were used as the reference genes. Primer sequences and annealing temperatures were based on (Sztatelman et al., 2015) and are listed in Table S1 (at https://ojs.ptbioch.edu. $\mathrm{pl} /$ index.php/abp/). cDNA pooled from six different samples (darkened and non-darkened leaves) was used as a reference for calculating relative gene expression levels. Normalization was performed using normalization factors based on reference gene levels, calculated using geNorm v3.4 (Vandesompele et al., 2002).

Protein extraction and Western blot. Leaf samples were homogenized and adjusted to an equal mass. Proteins were extracted as described by Sakamoto and Briggs (Sakamoto \& Briggs, 2002). SDS-PAGE was performed on $12 \%$ polyacrylamide gels and was followed by a semi-dry protein transfer (BioRad) to a PVDF membrane. The membrane was blocked overnight with $5 \%(\mathrm{w} / \mathrm{v})$ non-fat powdered milk in phosphate-buffered saline (PBS), $0.5 \%$ Tween-20. Primary antibodies, anti PsbaA (D1 protein, Agrisera AS05084A), were applied at a dilution of 1:10000 
(a)

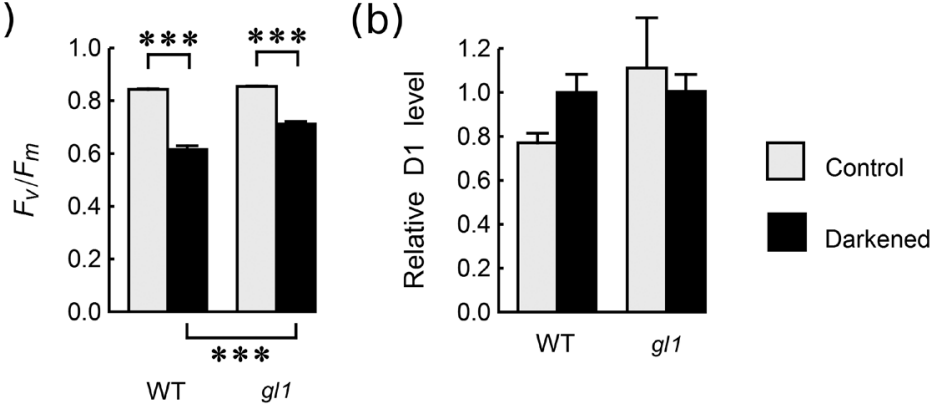

Figure 1. (a) Maximum quantum yield of PSII $\left(F_{v} / F_{m}\right)$ and (b) relative PSII D1 protein levels in the control and 4-day-darkened leaves of WT and gl1 $A$. thaliana plants.

(a) Each bar corresponds to an average of 40-43 biological replicates. Error bars =S.E. Asterisks indicate statistically significant differences of means ( $P$ values adjusted with the Hankel method: ${ }^{*} P=0.01-0.05$; ${ }^{* *} P=0.001-0.01$, $\left.{ }^{* * *} P<0.001\right)$. (b) Each bar corresponds to an average of 6 biological replicates. The D1 protein level in wild type leaves kept in light was set to 1 . Error bars $=$ S.E. Asterisks indicate statistically significant differences of means of the log-transformed values ( $P$ values adjusted with the Hankel method: $\left.{ }^{*} P=0.01-0.05 ;{ }^{* *} P=0.001-0.01,{ }^{* * *} P<0.001\right)$.

(Agrisera) at room temperature for $1 \mathrm{~h}$. After washing, secondary antibodies (goat anti-rabbit horseradish peroxidase (HRP) conjugated IgG, Agrisera) were applied at a dilution of 1:10000, at room temperature for $1 \mathrm{~h}$. The signal was detected with Clarity Western ECL Blotting Substrate (Bio-Rad) and the BioSpectrum Imaging System (UVP Ultra-Violet Products Ltd). Then, the membranes were stripped with Restore Plus Western Blot Stripping Buffer (Thermo Scientific) and probed again with anti-actin antibody (AS132640, Agrisera) at a dilution of 1:2500, at room temperature for $1 \mathrm{~h}$, followed by incubation with secondary antibodies and ECL detection. Densitometric quantification was performed using ImageJ. Intensities of the chemiluminescent signals were normalized to actin levels in each sample.

Statistical analysis. The significance of the effects of the plant line (WT, gl1) and light conditions (control, darkened) was calculated with two-way ANOVA using the $\mathrm{R}$ software. The significance of the four pairwise differences of means (WT control vs WT darkened, gll control vs gll darkened, WT control vs gll control and WT darkened vs gll darkened) was tested using the glht command of the multcomp package. Holm's correction was used to adjust the $p$-values for multiple comparisons. In general, variance was not uniform across groups. Thus, the heteroskedasticityconsistent variance - covariance matrix was used in the pairwise comparison procedure, calculated using the sandwich library. The results of the expression ex- periments ( $\mathrm{mRNA}$ and protein levels) were $\log -$ transformed before statistical analysis.

\section{RESULTS}

\section{Photosynthetic efficiency}

Photosynthetic efficiency, measured as $\mathrm{F}_{\mathrm{v}} / \mathrm{F}_{\mathrm{m}}$, was comparable in WT and gll plants grown under the control conditions. In the darkened leaves of both genotypes, the $\mathrm{F}_{\mathrm{v}} / \mathrm{F}_{\mathrm{m}}$ parameter values were significantly lower. However, the decrease in $\mathrm{F}_{\mathrm{v}} /$ $\mathrm{F}_{\mathrm{m}}$ was smaller in gll and the difference between both genotypes was statistically significant at the level of 0.001 (Fig. 1a). Additionally, we assessed the levels of the photosynthetic D1 protein, a core subunit of PSII (Fig. 1b). In control plants the amount of D1 was visibly higher in $g / 1$ than in W'T. After leaf darkening the amount of D1 increased in the WT plants and it slightly decreased in $g / 1$, resulting in equal amounts of protein in both genotypes. However, all observed differences in the D1 protein levels between WT and gll plants were statistically non-significant (Fig. 1b).

\section{Photosynthetic pigments}

After four days of darkening, the leaves of both, the WT and gll, showed partial yellowing indicating a change in photosynthetic pigment composition (Fig. S1 at https://ojs.ptbioch.edu.pl/index.php/abp/). The contents of all analyzed photosynthetic pigments (chlorophyll a and $b$, neoxanthin, violaxanthin, $\beta$-carotene and lutein) per $g$ of fresh weight were comparable in the WT and gl1 light-grown plants. After leaf darkening, the content of all pigments per fresh weight was visibly reduced, especially in the case of both chlorophylls and $\beta$-carotene (by up to $50 \%$ ) (Fig. $2 \mathrm{a}-\mathrm{c}$ ). This decrease was found to be statistically significant in the case of almost all pigments (apart from violaxanthin) in the WT plants (Fig. 2b). Although in gl1 plants the differences between control and darkened leaves were not statistically significant, the decrease in pigment content was also visible, suggesting the same process occurred as in the WT plants (Fig. 2). The seemingly minor differences between both genotypes were more pronounced when the pigment content was expressed per amount of total chlorophyll (Fig. S2b-c https://ojs.ptbioch.edu.pl/index.php/ (a)

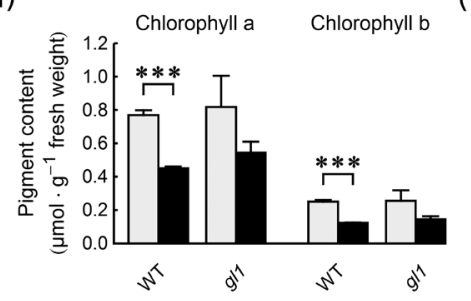

(b)

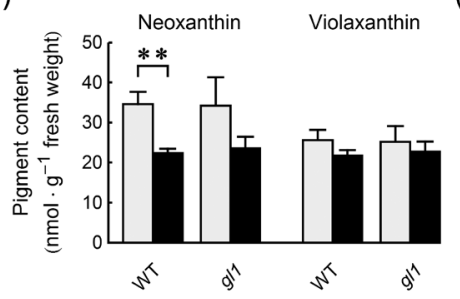

(c)

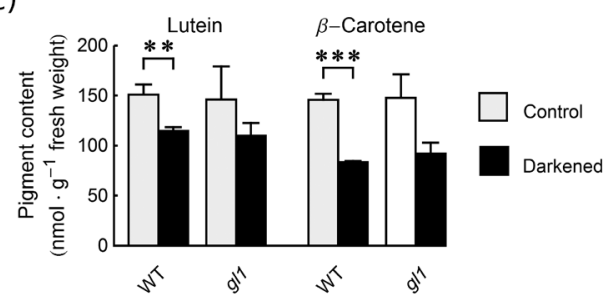

Figure 2. Photosynthetic pigment content: (a) chlorophyll $a$ and chlorophyll $b$, (b) neoxanthin and violaxanthin, (c) lutein and $\beta$-carotene, in the control and 4-day-darkened leaves of WT and gl1 A. thaliana plants.

Each bar corresponds to an average of 4 biological replicates. Asterisks indicate statistically significant differences of means $(P$ values adjusted with the Hankel method: $\left.{ }^{*} P=0.01-0.05 ;{ }^{* *} P=0.001-0.01,{ }^{* * *} P<0.001\right)$. 

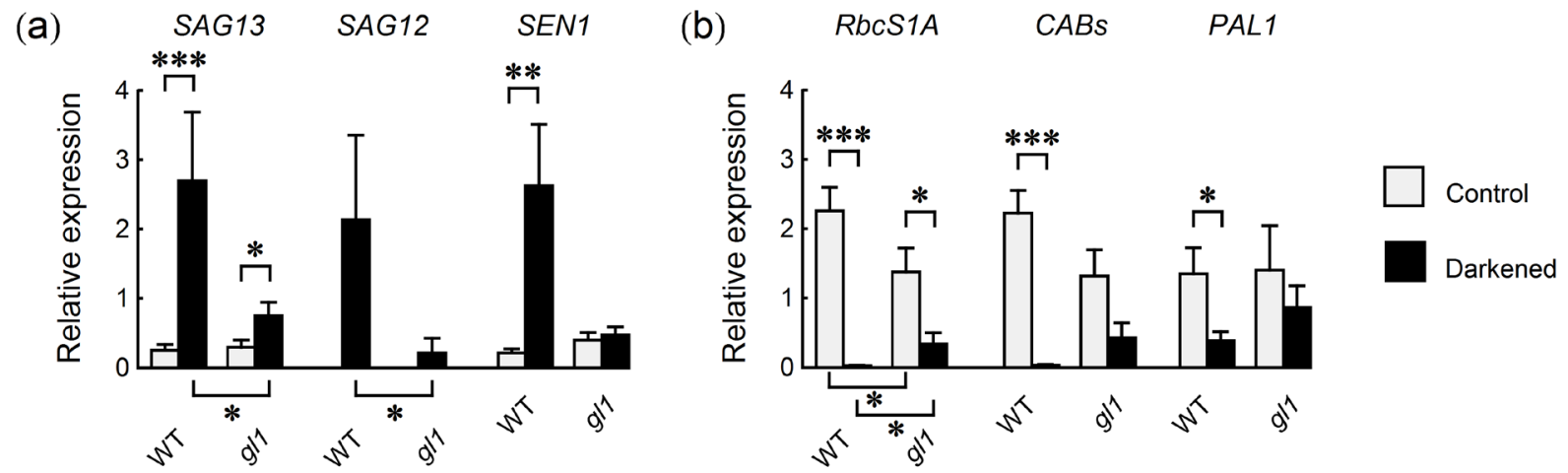

Figure 3. Relative expression of genes associated with (a) senescence (SAG13, SAG12, SEN1), (b) photosynthesis (RbcS1, CABs) and anthocyanin synthesis (PAL1), at the mRNA level in the control and 4-day-darkened leaves of WT and gl1 $A$. thaliana plants.

Each bar corresponds to an average of 12 biological replicates. Asterisks indicate statistically significant differences of means of the log-transformed values ( $P$ values adjusted with the Hankel method: $\left.{ }^{*} P=0.01-0.05 ;{ }^{* *} P=0.001-0.01,{ }^{* * *} P<0.001\right)$.

abp/). In the light-grown W'T and gll plants all pigment content ratios were comparable (Fig. S2a-c at https:// ojs.ptbioch.edu.pl/index.php/abp/). After darkening, the content of carotenoids (neoxanthin, violaxanthin and lutein) in relation to chlorophyll had increased, while the $\beta$-carotene:chlorophyll ratio remained unchanged (Fig. S2 https://ojs.ptbioch.edu.pl/index.php/abp/). The darkinduced increase in carotenoid:chlorophyll ratios was slightly higher in the WT plants than in gll (Fig. S2bc at https://ojs.ptbioch.edu.pl/index.php/abp/). In the case of violaxanthin and lutein, the differences between the control and darkened plants were statistically significant for both, the W'T and gll (Fig. S2b-cat at https:// ojs.ptbioch.edu.pl/index.php/abp/).

\section{Expression of genes involved in photosynthesis and senescence}

To check whether the observed changes in pigment content and photosynthetic efficiency were associated with the dark-induced process of senescence, the expression of three senescence marker genes was assessed: SAG13, SAG12 and SEN1 (Oh et al., 1996; Weaver et al., 1998) (Fig. 3a). In control plants only $S A G 13$ and SEN1 were expressed, the transcript levels being similar in the WT and gll plants (Fig. 3a). After leaf darkening, both genes were strongly upregulated (12- and 15fold respectively) in the WT plants, whereas in gll only a 2-fold increase in $S A G 13$ expression was observed (Fig. 3a). Dark treatment also induced the expression of $S A G 12$, with an almost 6-fold higher transcript level in WT as compared to gl1 (Fig. 3a). In the case of $S A G 13$ and $S A G 12$, expression levels in the darkened WT leaves were significantly higher than in $g l 1$.

We also tested the expression of genes associated with photosynthesis $(\mathrm{R} b c S 1 A, C A B s)$ or known to be induced by light (PAL1) (Jones, 1984; Kimura et al., 2003) (Fig. 3b). In the light-grown plants the levels of $\operatorname{RbcS1} A$ and $C A B s$ transcripts were slightly lower in gl1 than in the WT, and the expression of PAL1 was comparable in both genotypes (Fig. 3b). Leaf darkening caused the downregulation of all three genes. In most cases the effect was statistically significant, except for PAL1 expression in gl1 where the decrease was relatively small (Fig. $3 \mathrm{~b}$ ). The dark-induced downregulation of the tested genes was visibly stronger in the WT plants, the effect being statistically significant in the case of RBCS1A (Fig. 3b). Thus, for all three genes, the differences between transcript levels in the control and darkened plants were greater in W'T than in $g l 1$.

\section{DISCUSSION}

Until recently, physiological and molecular studies of the $A$. thaliana glabra1 mutant were restricted to the process of trichome formation and some other effects related to the leaf structure (Xia et al., 2010; Tsuji \& Coe, 2013). To our knowledge, other aspects of the mutant's physiology, including the progress of senescence, have not been investigated in more detail to date.

The experimental scheme of darkening individual leaves on growing plants applied here has been established as a good model of natural senescence (Weaver \& Amasino, 2001; van der Graaff et al., 2006; Keech et al., 2007). While whole darkened plants seem to enter a 'stand-by' mode, aimed to preserve the activity of crucial metabolic pathways for as long as possible, the darkening of individual leaves triggers the degradation of cellular components and nutrient retrieval (Keech et al., 2007). This is reflected in a rapid decline in photosynthetic activity. Similarities between natural and dark-induced senescence in individual leaves have been confirmed by a transcriptome study, showing at the same time that the former process is much more complex (van der Graaff et al., 2006).

WT and gl1 plants, when grown under control conditions, were comparable by all parameters tested. The only pronounced difference was the lower expression of RbcS1 $A$ and $C A B s$ in gll (Fig. 3b), which did not affect the photosynthetic efficiency measured as $\mathrm{F}_{\mathrm{v}} / \mathrm{F}_{\mathrm{m}}$ (Fig. 1a). This allows us to assume that all the differences observed between both genotypes after leaf darkening are truly linked to differences in the process of senescence. The significantly higher value of the $\mathrm{F}_{\mathrm{v}} / \mathrm{F}_{\mathrm{m}}$ parameter in the darkened gl1 leaves as compared to WT was the first hint to a slower progress of senescence in mutant plants. The decline in photosynthetic activity in darkened leaves was not reflected in the levels of the D1 protein which increased in the WT and only slightly decreased in gll (Fig. 1b). Lower photosynthetic efficiency in darkened leaves was correlated with the downregulation of $\operatorname{RbcS1A}$ and $C A B s$ photosynthetic genes (Fig. $3 \mathrm{~b}$ ), which is consistent with results of previous similar studies (Weaver \& Amasino, 2001; Sztatelman et al., 2015). This suggests that although the biosynthesis of new components has already been inhibited, the degradation of the photosynthetic ma- 
chinery might not be significantly advanced yet. Higher $\mathrm{R} b \mathrm{~s} 1 \mathrm{~A}$ and $\mathrm{CABs}$ transcript levels in the darkened $g / 1$ leaves as compared with the WT ones further point to a slower progress of senescence in these plants. This effect was statistically significant in the case of $\mathrm{R} b \mathrm{c} S 1 \mathrm{~A}$. Degradation of the D1 protein is also known to be induced by abiotic stresses, such as excessive light, UV-B radiation or high salinity (Kato \& Sakamoto, 2009; Sakuraba et al., 2014; Sztatelman et al., 2015). The lack of an evident decrease in D1 levels and the absence of degradation products may therefore mean that the applied dark treatment specifically triggers senescence, without being an additional source of stress. The PAL1 gene is involved in anthocyanin biosynthesis and induced by light (Jones, 1984; Kimura et al., 2003). Downregulation of this gene in darkness probably reflects the reduced need for the production of photoprotective pigments under these conditions. The small decrease in PAL1 transcript level, observed in the darkened gll leaves, may therefore be another indicator of slower senescence in these plants (Fig. 3b).

Natural senescence is invariably connected with gradual leaf yellowing. This could be also observed in our experimental model (Fig. S1 at https://ojs.ptbioch.edu. $\mathrm{pl} /$ index.php/abp/). This leaf yellowing is due to the degradation of photosynthetic pigments, which contributes to the decline in photosynthetic activity. This was confirmed by the analysis of photosynthetic pigment content. As expected, the levels of all pigments had decreased substantially after dark treatment (Fig. 2). No major, significant differences could be observed in the reaction to darkening between $g / 1$ and WT. In both genotypes, an increase in the amount of carotenoids (neoxanthin, violaxanthin and lutein) as compared to total chlorophyll content was observed after leaf darkening, which is consistent with the usually faster degradation of chlorophylls (Young et al., 1991; Lu et al., 2001) (Fig. S2b-c at https://ojs.ptbioch.edu.pl/index.php/abp/). This parameter revealed some subtle differences between the WT and gll plants. A slightly higher amount of chlorophylls after darkening in gll leaves as compared to WT (Fig. 2a) is also reflected in lower violaxanthin, neoxanthin and lutein ratio to total chlorophyll in the darkened gll leaves (Fig. S2b-c at https://ojs.ptbioch.edu.pl/index. $\mathrm{php} / \mathrm{abp} /$ ). This points to a slower decay of chlorophylls as compared with other photosynthetic pigments in $g / 1$, thus supporting the assumption of delayed senescence in this mutant. An increase in the chlorophyll a:chlorophyll $b$ ratio in the darkened leaves, typical for senescence, was comparable in the WT and gll plants (Fig. S2a at https://ojs.ptbioch.edu.pl/index.php/abp/) (Pružinská et al., 2005). It indicates that in both genotypes, in darkness chlorophyll b was degraded faster than chlorophyll $a$. As the chlorophyll a/chlorophyll $b$ ratio reflects the PSI/ PSII antennae stoichiometry (Pfannschmidt et al., 2001), we may also postulate that there is no selective degradation of one photosystem in both genotypes tested.

To confirm the observed slower senescence in darkened gll leaves we assessed the expression of three senescence marker genes: SAG12, SAG13 and SEN1 (Fig. 3a). All of them were upregulated (SAG13, SEN1) or induced ( $S A G 12)$ during leaf darkening (Oh et al., 1996; Weaver et al., 1998). Low expression of $S A G 13$ and the absence of $S A G 12$ transcript in control plants is consistent with the respective roles of these genes as early and late senescence markers (Weaver et al., 1998). $S A G 12$ is also considered to be the most specific marker for natural senescence, which is in line with the observed expression pattern (transcript detected only in the darkened leaves). The SEN1 gene, apart from being an- other senescence marker, is also thought to be involved in a direct response to darkness (Oh et al., 1996). A significantly lower expression of all three genes in the darkened gli leaves when compared to WT provides overwhelming evidence for the delayed senescence in this mutant.

The results obtained in this work provide ample and robust evidence that the onset and progress of darkinduced senescence is delayed in the $A$. thaliana glabra1 mutant. Taking into account previous reports comparing different models of senescence (Weaver \& Amasino, 2001; van der Graaff et al., 2006), it is highly probable that the same holds true for the process of natural senescence in these plants. The lack of trichomes makes the gll mutant more susceptible to numerous environmental stresses, both abiotic and biotic, which may contribute to the induction of senescence in these plants (Hauser, 2014; Bickford, 2016). Nevertheless, trichome production comes at a cost (Sletvold et al., 2010; Hauser, 2014). Although the presence of trichomes may be beneficial to the plant, they are developed at the expense of other traits. As demonstrated in Arabidopsis lyrata, trichome density (and the resulting resistance to herbivores) was negatively correlated with plant size and fitness (Sletvold et al., 2010). Perhaps in the case of the gll mutant, the resources which would otherwise be used for trichome production can be allocated to other processes. This could explain a higher PSII efficiency and slower progress of senescence in the darkened gll leaves. On the other hand, taking into account the nature of GLABRA1 as a transcription factor, its direct role in regulating the expression of genes involved in senescence cannot be excluded. It is also possible that both of the proposed (and perhaps also other) mechanisms contribute to the observed delayed senescence in the gll mutant.

The demonstrated effect of the g/1 mutation on the process of senescence should be taken into account in any experiments using other mutants with a gll genetic background and the results should be interpreted with caution. The gll example shows that a single mutation can affect very different, seemingly unrelated processes. It is therefore advisable to avoid using such "cryptic" multiple mutants. If this is impossible, an appropriate control, that is the gl1 mutant, should be used.

\section{Conflict of Interest Disclosures}

The authors declare no conflict of interest.

\section{REFERENCES}

Bickford CP (2016) Ecophysiology of leaf trichomes. Funct Plant Biol 43: 807-814. https://doi.org/10.1071/FP16095

Dai X, Zhou L, Zhang W, Cai L, Guo H, Tian H, Schiefelbein J, Wang S (2016) A single amino acid substitution in the R3 domain of GLABRA1 leads to inhibition of trichome formation in Arabidopsis without affecting its interaction with GLABRA3. Plant Cell Environ 39: 897-907. https://doi.org/10.1111/pce.12695

Hauser MT (2014) Molecular basis of natural variation and environmental control of trichome patterning. Front Plant Sci 5: 320. https://doi.org/10.3389/fpls.2014.00320

Herman PL, Marks MD (1989) Trichome development in Arabidopsis thaliana. II. Isolation and complementation of the GLABROUS1 gene. Plant Cell 1: 1051-1055. https://doi.org/10.1105/tpc.1.11.1051

Jones DH (1984) Phenylalanine ammonia-lyase: regulation of its induction, and its role in plant development. Phytochemistry 23: 1349-1359. https://doi.org/10.1016/S0031-9422(00)80465-3

Kato Y, Sakamoto W (2009) Protein quality control in chloroplasts: a current model of D1 protein degradation in the photosystem II repair cycle. J Biochem 146: 463-469. https://doi.org/10.1093/jb/ mvp073

Keech O, Pesquet E, Ahad A, Askne A, Nordvall DAG, Vodnala SM, Tuominen H, Hurry V, Dizengremel P, Gardestroem P (2007) The 
different fates of mitochondria and chloroplasts during dark-induced senescence in Arabidopsis leaves. Plant Cell Environ 30: 1523-1534. https://doi.org/10.1111/j.1365-3040.2007.01724.x

Kimura M, Yamamoto YY, Seki M, Sakurai T, Sato M, Abe T, Yoshida S, Manabe K, Shinozaki K, Matsui M (2003) Identification of Arabidopsis genes regulated by high light-stress using cDNA microarray. Photochem Photobiol 77: 226-233. https://doi.org/10.1562/00318655(2003)0770226IOAGRB2.0.CO2

Koornneeff M, Dellaert LWM, Van der Veen JH (1982) EMS-and relation-induced mutation frequencies at individual loci in Arabidopsis thaliana (L.) Heynh. Mut Res-Fund Mol M 93: 109-123. https://doi. org/10.1016/0027-5107(82)90129-4

Lu C, Lu Q, Zhang J, Kuang T (2001) Characterization of photosynthetic pigment composition, photosystem II photochemistry and thermal energy dissipation during leaf senescence of wheat plants grown in the field. J Exp Bot, 52: 1805-1810. https://doi. org/10.1093/jexbot/52.362.1805

Labuz J, Sztatelman O, Banaś AK, Gabryś H (2012) The expression of phototropins in Arabidopsis leaves: developmental and light regulation. J Exp Bot 63: 1763-1771. https://doi.org/10.1093/jxb/ers061

Marks MD, Feldmann KA (1989) Trichome development in Arabidopsis thaliana. I. T-DNA tagging of the GLABROUS1 gene. Plant Cell 1: 1043-1050. https://doi.org/10.1105/tpc.1.11.1043

Matías-Hernández L, Aguilar-Jaramillo AE, Cigliano RA, Sanseverino W, Pelaz S (2016) Flowering and trichome development share hormonal and transcription factor regulation. J Exp Bot 67: 1209-1219. https://doi.org/10.1093/jxb/erv534

Oh SA, Lee SY, Chung IK, Lee CH, Nam HG (1996) A senescenceassociated gene of Arabidopsis thaliana is distinctively regulated during natural and artificially induced leaf senescence. Plant Mol Biol 30: 739-754. https://doi.org/10.1007/BF00019008

Oppenheimer DG, Herman PL, Sivakumaran S, Esch J, Marks MD (1991) A myb gene required for leaf trichome differentiation in Arabidopsis is expressed in stipules. Cell 67: 483-493. https://doi. org/10.1016/0092-8674(91)90523-2

Pfannschmidt T, Schütze K, Brost M, Oelmüller R (2001) A novel mechanism of nuclear photosynthesis gene regulation by redox signals from the chloroplast during photosystem stoichiometry adjustment. J Biol Chem 276: 36125-36130. https://doi.org/10.1074/jbc. M105701200

Pružinská A, Tanner G, Aubry S, Anders I, Moser S, Müller T, Ongania H-K, Kräutler B, Youn J-Y, Liljegren SJ, Hörtensteiner S (2005) Chlorophyll breakdown in senescent Arabidopsis leaves. Characterization of chlorophyll catabolites and of chlorophyll catabolic enzymes involved in the degreening reaction. Plant Physiol 139: 52-63. https://doi.org/10.1104/pp.105.065870

Redei GP, Y Hirono (1964) Linkage studies. Arab Inf Serv, 1: 9-10.
Sakamoto K, Briggs WR (2002) Cellular and subcellular localization of phototropin 1. Plant Cell 14: 1723-1735. https://doi.org/10.1105/ tpc.003293

Sakuraba Y, Lee SH, Kim YS, Park OK, Hörtensteiner S, Paek NC (2014) Delayed degradation of chlorophylls and photosynthetic proteins in Arabidopsis autophagy mutants during stress-induced leaf yellowing. J Exp Bot 65: 3915-3925. https://doi.org/10.1093/jxb/ eru008

Sletvold N, Huttunen P, Handley R, Kärkkäinen K, Ågren J (2010) Cost of trichome production and resistance to a specialist insect herbivore in Arabidopsis lyrata. Evol Ecol 24: 1307-1319. https:// doi.org/10.1007/s10682-010-9381-6

Sztatelman O, Grzyb J, Gabryś H, Banaś AK (2015) The effect of UV-B on Arabidopsis leaves depends on light conditions after treatment. BMC Plant Biol 15: 281. https://doi.org/10.1186/s12870-0150667-2

Tsuji J, Coe L (2013) The glabra1 mutation affects the stomatal patterning of Arabidopsis thaliana rosette leaves. Bios 84: 92-98. https://doi. org/10.1893/0005-3155-84.2.92

van der Graaff E, Schwacke R, Schneider A, Desimone M, Flügge UI, Kunze R (2006) Transcription analysis of Arabidopsis membrane transporters and hormone pathways during developmental and induced leaf senescence. Plant Physiol 141: 776-792. https://doi. org/10.1104/pp.106.079293

Vandesompele J, De Preter K, Pattyn F, Poppe B, Van Roy N, De Paepe A, Speleman F (2002) Accurate normalization of real-time quantitative RT-PCR data by geometric averaging of multiple internal control genes. Genome Biol 3: research0034. https://doi. org/10.1186/gb-2002-3-7-research0034

Weaver LM, Amasino RM (2001) Senescence is induced in individually darkened Arabidopsis leaves, but inhibited in whole darkened plants. Plant Physiol 127: 876-886. https://doi.org/10.1104/pp.010312

Weaver LM, Gan S, Quirino B, Amasino RM (1998) A comparison of the expression patterns of several senescence-associated genes in response to stress and hormone treatment. Plant Mol Biol 37: 455-469. https://doi.org/10.1023/A:1005934428906

Xia Y, Yu K, Navarre D, Seebold K, Kachroo A, Kachroo P (2010) The glabra1 mutation affects cuticle formation and plant responses to microbes. Plant Physiol 154: 833-846. https://doi.org/10.1104/ pp.110.161646

Young AJ, Wellings R, Britton G (1991) The fate of chloroplast pigments during senescence of primary leaves of Hordeum vulgare and Avena sativum. J Plant Physiol 137: 701-705. https://doi.org/10.1016/ S0176-1617(11)81225-3

Yu N, Cai WJ, Wang S, Shan CM, Wang LJ, Chen XY (2010) Temporal control of trichome distribution by microRNA156-targeted SPL genes in Arabidopsis thaliana. Plant Cell 22: 2322-2335. https://doi. org/10.1105/tpc.109.072579 